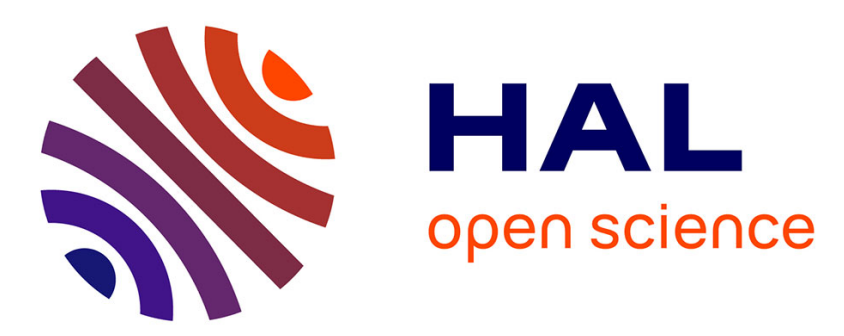

\title{
View point on hydrothermal sintering: Main features, today's recent advances and tomorrow's promises
}

Graziella Goglio, Arnaud Ndayishimiye, Alain Largeteau, Catherine Elissalde

\section{To cite this version:}

Graziella Goglio, Arnaud Ndayishimiye, Alain Largeteau, Catherine Elissalde. View point on hydrothermal sintering: Main features, today's recent advances and tomorrow's promises. Scripta Materialia, 2019, 158, pp.146-152. 10.1016/j.scriptamat.2018.08.038 . hal-01875477

\section{HAL Id: hal-01875477 \\ https://hal.science/hal-01875477}

Submitted on 6 Oct 2020

HAL is a multi-disciplinary open access archive for the deposit and dissemination of scientific research documents, whether they are published or not. The documents may come from teaching and research institutions in France or abroad, or from public or private research centers.
L'archive ouverte pluridisciplinaire HAL, est destinée au dépôt et à la diffusion de documents scientifiques de niveau recherche, publiés ou non, émanant des établissements d'enseignement et de recherche français ou étrangers, des laboratoires publics ou privés. 


\title{
View point on hydrothermal sintering: Main features, today's recent advances and tomorrow's promises
}

\author{
Graziella Goglio* , Arnaud Ndayishimiye, Alain Largeteau, Catherine Elissalde \\ CNRS, Univ. Bordeaux, ICMCB, UMR 5026, 87 avenue du Dr A. Schweitzer, 33608 Pessac, France \\ Corresponding author : graziella.goglio@u-bordeaux.fr \\ Tel : +33(0)540006334 \\ Fax : + $33(0) 540002761$
}

\begin{abstract}
The development of new high performance materials faces the challenge of implementing low temperature densification processes to overcome current technological limitations. In this context, the hydrothermal sintering, inspired by the natural processes of geological and biological mineralization, has recently emerged as a major opportunity to develop new and/or optimized materials that respond to today's scientific, technological and related socio-economic issues. The purpose of this viewpoint paper is to present opinions and propose future outlook for hydrothermal sintering based on the most recent achievements.
\end{abstract}

\section{Key words:}

Hydrothermal Sintering, Low-Temperature Water-Assisted Densification, Ceramics, Nanostructuration, Low-Temperature Sintering Process 
New materials have always accompanied scientific and technical progress. Currently, research is directed towards materials with new properties, improved performance to cost ratio, limited environmental impact over their entire life cycle. More particularly, ceramics and high performance assemblies have a major impact in automotive, electronic applications, energy and environment, mechanical engineering, medical technology... These materials, due to their exceptional properties, are able to meet the specific requirements of different applications, especially when a high level of functionality and reliability is required. These ceramic-type materials are oxides, sulfates, carbonates, phosphates, silicates, non-oxides and can be crystallized or amorphous.

The development of new high-performance ceramics, but also the design of complex assemblies, requires the mastery of the shaping processes, including suitable sintering processes. Currently most of advanced ceramic materials are fabricated from powders and sintered above $1000^{\circ} \mathrm{C}$ to reach at least $95 \%$ of their theoretical densities. The decrease in surface free energy, which is a driving force for sintering, might be promoted either by applying pressure or by enhancing diffusional processes using fast heating routes. Thus, intense international research has led to the development of numerous sintering techniques to enhance the performances of conventional sintering (CS) such as two-step (TSS), flash (FS), high pressure (HPS), spark plasma (SPS), rate controlled (RCS), microwave (MWS) sintering...[1-6] If it is well admitted that pressure is beneficial for densification via particle sliding and rearrangement, plastic deformation, and pore shrinkage, the high temperatures required by these processes create several technological barriers: (i) advanced materials need to be produced by energyand cost-efficient processes to ensure the feasibility of industrial scalability, (ii) materials that are metastable or that decompose at low temperature are difficult to sinter with such processes and (iii) co-sintering of multimaterials is hindered by differences in thermal stability, the rate and the onset temperature of shrinkage, and the physical and/or chemical compatibilities between the components [7-8].

To decrease these processing temperatures, the use of nanopowders (with particle size in the range 10 - $100 \mathrm{~nm}$ [9]) as starting materials appears as a key solution since the high surface-to-volume ratio of nanoparticles provides a strong driving force to promote the diffusion process, especially at elevated temperatures [10]. Another advantage of nanostructured ceramics is that, unlike the conventional technical ceramics, the pore volume fraction should be limited below a few tens of ppm [11]. It was shown that oxide nanoparticles with equiaxed morphology and narrow size distribution are a prerequisite to form green pellets with homogeneous density and low pore-to-particle size ratio, and thus to optimize the final relative density of the nanoceramics while preserving the initial nanograin size at full densification [11]. Finally one should consider that the use of nanoparticles is a route to design increasingly performing ceramics, providing a deep knowledge of the impact of the nanoscale structure on bulk properties. The recent advances in processing high quality nanocrystalline powders have favored the design of well controlled functional nanoceramics [12].

However, the decrease of the sintering temperature associated with the use of nanopowders is limited when full densification is targeted and high temperatures are still required to achieve densification. Consequently, one should consider that the competition between densification, coarsening processes 
and agglomeration often yields microstructures with overly coarse grains, which is detrimental to densification [13].

Then it appears clearly that an indisputable breakthrough in the sintering approaches would consist in combining pressure (below $350 \mathrm{MPa}$ ) and low temperature (at least below $500^{\circ} \mathrm{C}$ ). In this way, hydrothermal sintering appears as a powerful technology that surmounts the aforementioned barriers. First, similarly to advanced sintering processes such as SPS and hot pressing, this process uses an applied force to generate an internal pressure to improve particle rearrangement and densification of materials. It combines also the benefit of low temperatures that allow a better control of defects, prevent from solid state diffusion and grain growth and can be suitable for materials exhibiting low transition or decomposition temperatures. In addition, it overcomes the weakness of low temperature regime with respect to reactivity. Indeed, the main feature of hydrothermal sintering is to take advantage of hydrothermal conditions that promote diffusion of chemical species and optimize reactivity considered as an efficient driving force. The nature of solvent, the $\mathrm{pH}$ and the addition of mineralizers are then important levers to operate to optimize densification.

\section{1- A brief history on this geologically inspired process}

Dense ceramic materials can form in the nature under mild temperatures in the presence of water. As an example, besides biomineralization, the formation of ceramic-dense materials such as limestone also occurs in nature through large scale geological processes. Here the basic physicochemical mechanism may involve dissolution-precipitation process, referred to pressure solution creep, which relies on the mass transport from the contact zone between touching particles to the surrounding liquid phase and eventually to nearby non-contacting surfaces [14-18]. Consequently, the distance between the particle centres decreases, enabling global shrinkage and densification. The motion of ions during pressure solution creep is driven by the high-stress concentration at the contact point when the particle compact is subjected to an externally applied mechanical load. In response to such a stress concentration, ions at the contact point dissolve from the solid particle into the interfacial liquid film and eventually diffuse along the grain boundary before reaching the continuous liquid phase and precipitate on a lower-stressed particle surface. In addition, when the applied pressure is sufficiently high, plastic deformation through dislocation motion and/or viscous flow of the solid phase may participate to the densification process. It was shown that, for a given temperature, the densification rate is increased by reducing the particle size and increasing the applied pressure.

The hydrothermal sintering process is totally inspired from this geological process. It was first developed by N. Yamasaki et al. [19] and was called Hydrothermal Hot Pressing (Fig. 1.a). Here, a powder with water is externally and mechanically compressed in an autoclave, under hydrothermal conditions $\left(100^{\circ} \mathrm{C}<\mathrm{T}<350^{\circ} \mathrm{C} ; 22.5 \mathrm{MPa}<\mathrm{P}<220 \mathrm{MPa}\right.$ ) over short periods of time (from a few minutes to a few hours). As expected, the main driving force of such a process is the stress gradient within grains induced by external compression leading to the activation of the dissolution/precipitation phenomena at the solid/liquid interface. Here, water is expelled from the sample during densification and recovered in specific spaces for water retreat. Water both acts as a solvent, a pressure transmitting 
medium and a mass transport medium. Thus, hydrothermal conditions promote the reactivity at the solid/liquid interfaces, as diffusion processes in the solid phase are hindered at such low temperatures. This process was set up to densify metastable materials (anatase) [20-21], materials with mild temperature decomposition $\left(\mathrm{Ca} / \mathrm{SrCO}_{3}\right.$ [22-23], hydroxyapatite [24-25]), porous ceramics (porous hydroxyapatite [26], zeolites [27]), nanomaterials without coarsening $\left(\mathrm{Sn}_{1,24} \mathrm{Ti}_{1,94 \mathrm{O}_{3,66}}(\mathrm{OH})_{1,50} \mathrm{~F}_{1,42}\right.$ [28]), amorphous nanomaterials $\left(\mathrm{SiO}_{2}\right.$ [29-30]), tailored thermoelectric materials $\left(\mathrm{Ca}_{3} \mathrm{CO}_{4} \mathrm{O}_{9}\right.$ [31-32], $\mathrm{Na}_{x} \mathrm{Co}_{2} \mathrm{O}_{4}$ [33]) or to bond different materials (hydroxyapatite bonded to titanium [34] or to magnesium alloy [35]).

We have recently developed a new apparatus inspired by the hydrothermal hot pressing tool described by Yamasaki and Yanasigawa [19], but with improved performances due to the specific design of both the pistons and the autoclave (Fig. 1.b) [36]. Here, the glass-filled teflon gaskets are maintained below $100^{\circ} \mathrm{C}$, i.e. far from their maximum operating conditions $\left(300^{\circ} \mathrm{C}\right.$ ), thanks to a double system (cooling fins and water cooling circuit), so they can ensure the tightness of the system even when samples are submitted to higher temperatures. As a result, temperature and pressure can reach $500^{\circ} \mathrm{C}$ and $350 \mathrm{MPa}$, respectively [36]. Thanks to this optimization of the device, the range of experimental parameters is wide enough to tune the conditions to get either subcritical or supercritical solvent, which may have an influence on the elementary steps of the sintering. Depending on the nature of the solvent that can be either aqueous or non-aqueous, the process is called hydrothermal sintering or solvothermal sintering, respectively. These terms will be preferred to hydrothermal (or solvothermal) hot pressing because the word "hot" is contradictory with the experimental conditions applied and related induced mechanisms.
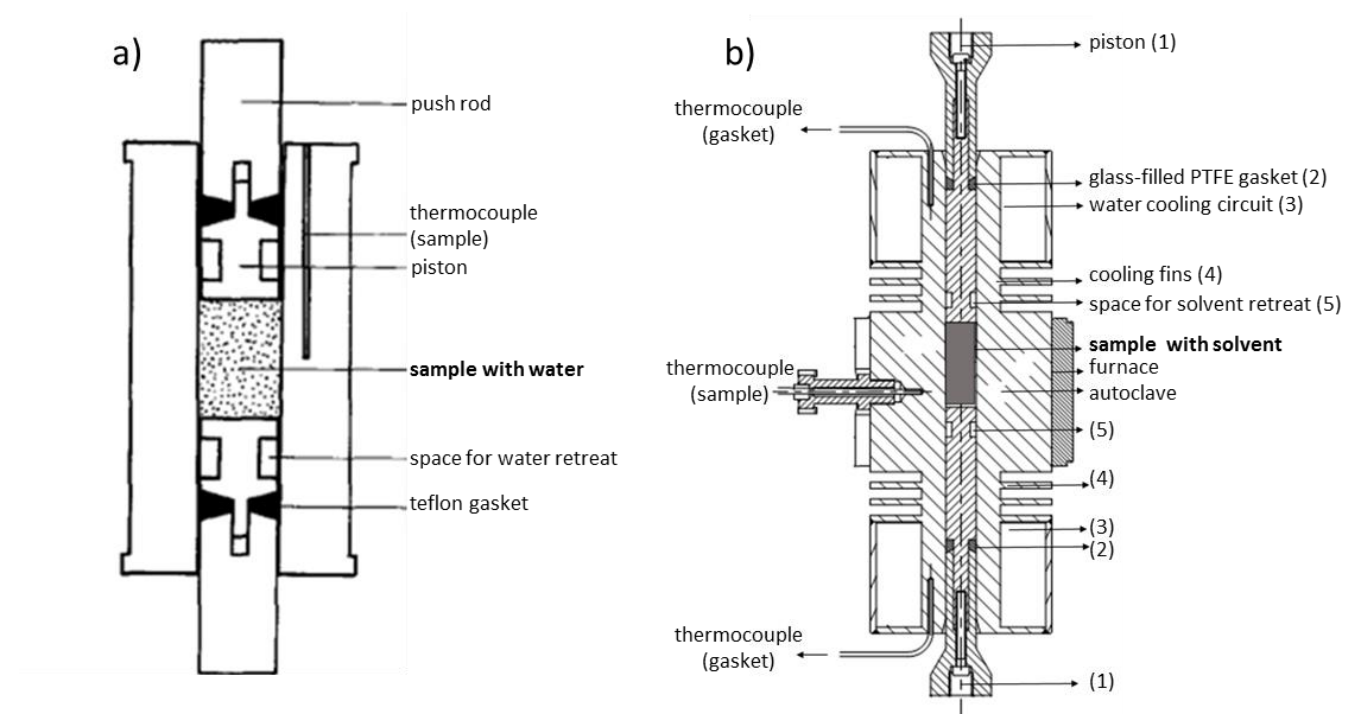

Fig. 1. Hydrothermal sintering apparatus designed by a) Yamasaki et al. [19] and b) Goglio et al. [36] In $b$ ), the design of pistons and specific cooling systems favor improved performances.

2- Recent advances on hydrothermal sintering. Illustration with the use of silica as a common thread

To explore all the potentialities of hydrothermal sintering and evaluate its adaptability towards the elaboration of a wide range of materials, we have focused on amorphous $50-70 \mathrm{~nm} \mathrm{\textrm {SiO } _ { 2 }}$ nanoparticles. 
They have been selected as starting powders because (i) they are considered as a suitable platform for tuning surface chemistry, (ii) they exhibit a spontaneous tendency for self-organization, (iii) they offer the possibility to study sintering with or without structural transition and (iv) the dissolution of silica (according to the equation $\mathrm{SiO}_{2}+2 \mathrm{H}_{2} \mathrm{O} \Rightarrow \mathrm{H}_{4} \mathrm{SiO}_{4}$ [37]) is congruent, which guarantees to exclude selective precipitation phenomena and makes the system easier to control.

\section{1- A synergy between mechanical-chemical effects and chemical ones driven by water}

The amount of water is a crucial parameter in hydrothermal sintering as it strongly influences the dissolution and mass transport steps. In this way, silica is a suitable for hydrothermal densification as the particles raw from synthesis are naturally hydrophilic due to their surface hydroxylation, which enhances the physisorption of water. Both physisorbed and chemisorbed water plays a crucial role during hydrothermal sintering [38]:

- the physisorbed water in the starting particles acts as the solvent and promotes dissolutionprecipitation. The amount of this weakly bonded water can be tuned by a previous calcination step of silica nanoparticles and strongly influences the spread of densification. If physisorbed water is removed from the silica sample before sintering experiment, the absence of inter particle neck growth is noticed after treatment at $300^{\circ} \mathrm{C}$ and $190 \mathrm{MPa}$ during 90 minutes, in full agreement with a high value of specific area close to that of starting powder $\left(54 \mathrm{~m}^{2} \cdot \mathrm{g}^{-1}\right.$ and $60 \mathrm{~m}^{2} \cdot \mathrm{g}^{-1}$, respectively). However, when the physisorbed water increases up to around $3 \mathrm{wt} \%$ and when same pressure and temperature sintering conditions are carried out, the mechanical-chemical process is strongly enhanced leading to a very dense microstructure with a reduced specific area to $14 \mathrm{~m}^{2} \cdot \mathrm{g}^{-1}$ and residual mesopores.

- the chemisorbed water related to surface hydroxylation favors chemical mechanisms enhanced under temperature and/or pressure and which act in synergy with the mechanical-chemical effects. The silanol groups both internal and at the surface of the particles and of the pores polycondensate hence leading to chemisorbed water departure and to the formation of siloxane bridges in particular between touching particles. These Si-O-Si inter particle bonds promote the neck formation, thus favoring the densification of the material. In the presence of a water excess that may be trapped into the macropores, the hydrophobic siloxane surface turns to hydrophilic due to a rehydration of the surface. A summary of the complementarity and synergy of the mechanical-chemical and chemical effects is schematically depicted in Fig. 2.

Obviously, this mechanical-chemical induced densification is more efficient when the nanoparticles are initially close packed (the green material being then mesoporous), in order to generate higher stress gradients. As a consequence, any stacking faults in the green material will generate residual macropores in the ceramic. The relative density of the green compact has then to be optimized to further promote the densification. In the case of silica, nanoparticles naturally self-organize during the compaction step. However, if water is added in the system, as-induced local turbulences may disturb this arrangement, favoring the formation of macroporosities in the ceramic [38]. 


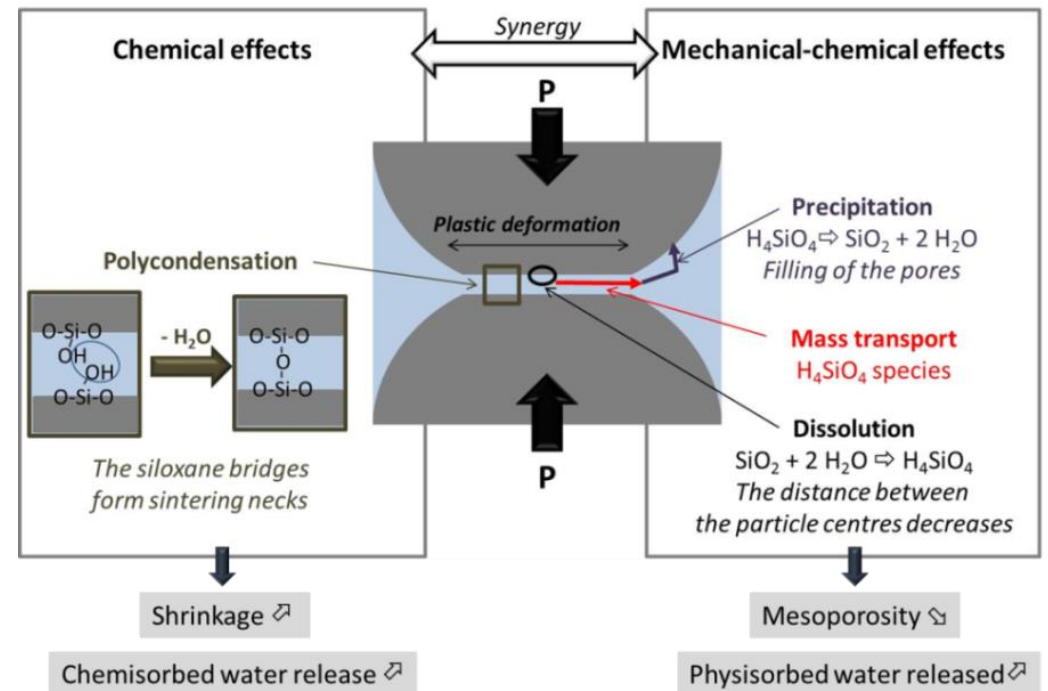

Fig. 2. Synergy between mechanical-chemical and chemical effects [38]

\section{2- A process governed by thermodynamical and chemical levers}

One main advantage of the process is related to the hydrothermal conditions which strongly promote the reactivity and the diffusion of species in the solvent. Obviously, classical thermodynamic parameters such as pressure and temperature act as important levers to tune these specific conditions. - In the case of naturally hydrated nanoparticles with or without added water, a higher relative density is observed when the hydrothermal sintering temperature is $300^{\circ} \mathrm{C} \mathrm{(Fig.} \mathrm{3).} \mathrm{On} \mathrm{the} \mathrm{one} \mathrm{hand,}$ below this temperature, the densification is limited by the dissolution due to a low solubility of silica in water; the observed residual mesopores result from the uncomplete filling of the interstices of the initial close packed assemblies. It has been observed that the densification begins around $200^{\circ} \mathrm{C}$. On the other hand, microstructural control deteriorates significantly beyond $300^{\circ} \mathrm{C}$ because of the released water departures increasingly important induced by the spread of densification (departure of additional water, physisorbed water and chemisorbed water released by polycondensation). The microstructure consequently accommodates these water releases via the formation of macropores in a material which is less dense as the temperature rises above $300^{\circ} \mathrm{C}$. Hence, because water remains liquid (or supercritical) throughout the overall process, it appears necessary to control each elementary step in order to find the best compromise between activated dissolution-precipitation mechanisms and the regulation of the water release. 

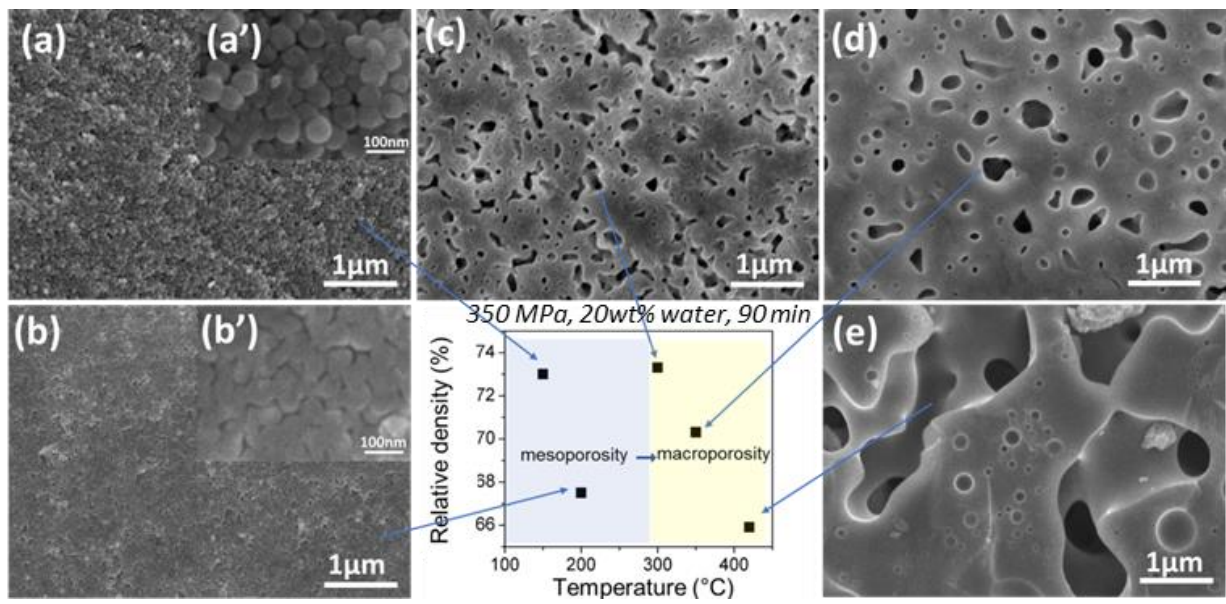

Fig. 3. Influence of the temperature (a) $150^{\circ} \mathrm{C}$, b) $\left.200^{\circ} \mathrm{C}, \mathrm{c}\right) 300^{\circ} \mathrm{C}$, d) $350^{\circ} \mathrm{C}$, e) $420^{\circ} \mathrm{C}$ ) on the densification of silica nanoparticles.

Zooms on the microstructures $a$ ) and b) are proposed on $a^{\prime}$ ) and $\left.b^{\prime}\right)$, respectively

- For hydrothermal sintering of $50 \mathrm{~nm}$-silica nanoparticles performed at $300^{\circ} \mathrm{C}$ during 90 minutes with $20 \mathrm{w} \%$ water, the relative density increases monotonically with pressure, from $63 \%$ at $100 \mathrm{MPa}$ up to $86 \%$ at $350 \mathrm{MPa}$ (Fig. 4). Pressure favors both mechanical-chemical and chemical effects. Because it contributes to improve the solubility and the dissolution kinetics, to increase the intra grain stress gradients, to facilitate polycondensation and to reduce the molar volume of water, pressure is indeed beneficial to densification and hinders the formation of macropores by regulating the water spread.
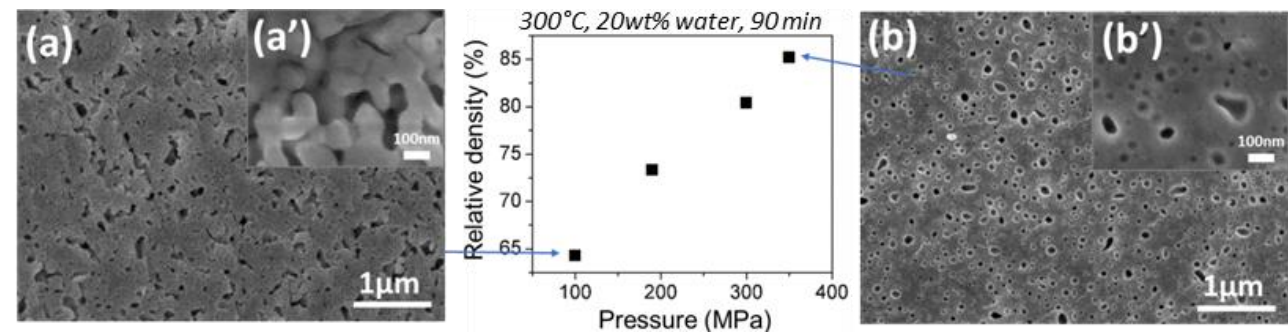

Fig. 4. Influence of the pressure on the densification of silica nanoparticles. The microstructures (with zoom on the inserts $\left.a^{\prime}\right)$ and $\left.b^{\prime}\right)$ ) observed for $100 \mathrm{MPa}$ and $350 \mathrm{MPa}$ are presented in a) and b), respectively.

Besides these thermodynamic parameters, hydrothermal sintering offers the main advantage to control the densification by chemical parameters.

- The use of a co-solvent makes possible to regulate the dissolution and precipitation steps. For example, the less polar nature of ethanol relative to water makes the dissolution weaker, thus favoring the precipitation in the vicinity of the zone of dissolution and leading to a slower propagation of the densification and to a slower release of the water. Moreover ethanol is more compressible than water which favors its transport into the matrix [39]. Consequently, the use of ethanol as a co-solvent favors a fine control of the microstructure through a change from macroporous matrix in the case of pure water to mesoporous one with a pore size all the more lower as the proportion of ethanol is high. When the sintering is performed at $300^{\circ} \mathrm{C}$ under $350 \mathrm{MPa}$ during 90 minutes with $20 \mathrm{wt} \%$ of solvent, 
the relative density reaches $88 \%$ with mesoporosity in the case of a mix made of 75 vol\% ethanol- 25 vol\% water, while it equals to $85 \%$ with macroporosity in the case of pure water (Fig. 5).

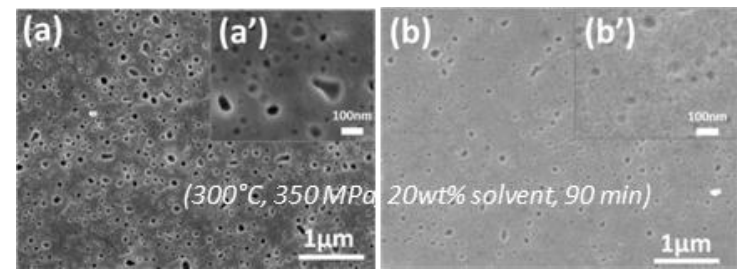

Fig. 5. Influence of the solvent on the densification with a) pure water and b) ethanol-water 75 vol\%25 vol\%

- A mineralizer can also be used to improve the dissolution step. In the case of silica, it is well known that the dissolution kinetics is strongly improved by a pH increase [40]. As a consequence, lowest $\mathrm{NaOH}$ concentrations favor the densification of amorphous silica, reaching $86 \%$ of relative density for $0.2 \mathrm{M}$ $\mathrm{NaOH}\left(300^{\circ} \mathrm{C}, 350 \mathrm{MPa}, 20\right.$ wt\% of solvent, Fig. 6.a) [41]. However, highest sodium hydroxide concentrations favor the stabilization of metastable $\alpha$-quartz. When the solvent is too basic, the dissolution is too fast in comparison to precipitation and diffusive mass transport is enhanced, leading to a highly densified heterogeneous microstructure (Fig. 6.c). However, quasi-complete densification of well-faceted $\alpha$-quartz grains with homogeneous nanometric size has been achieved for $2 \mathrm{M} \mathrm{NaOH}$ concentration, leading to $98 \%$ of relative density (Fig. 6.b) [41]. The epitaxial growth the grain boundaries is remarkable and characteristic for weak constraints (Fig. 6.d). Finally, a parallel can be made between hydrothermal crystal growth [42] and hydrothermal sintering of $\alpha$-quartz [41] where the driving force is the temperature gradient and the local pressure gradient, respectively. In both cases, the alkaline medium strongly favors the dissolution step by increasing the rate of dissolution.
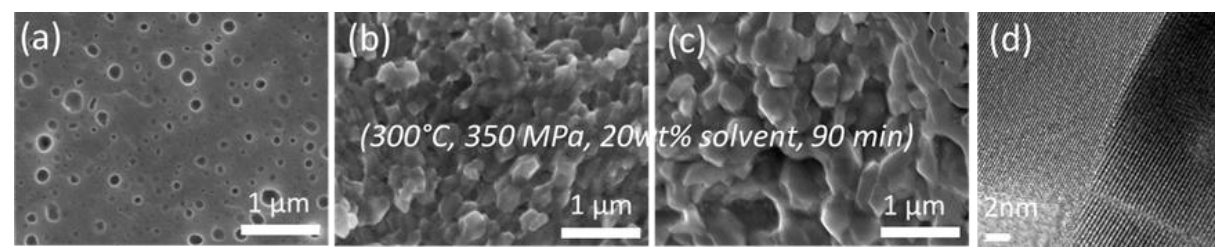

Fig. 6. HR-SEM of ceramics obtained after hydrothermal sintering of silica with 20 wt\% of a) $0.2 \mathrm{M}$ $\mathrm{NaOH}$, b) $2 \mathrm{M} \mathrm{NaOH}$ and c) $5 \mathrm{M} \mathrm{NaOH}$. d) HR-TEM image on sample b) [41]

\section{3-Design of complex multimaterials}

From a global point of view, one challenge is to perform the sintering of complex assemblies of materials that exhibit differences in their chemical and physical characteristics. In this way, in addition to any problems to solve for a single constituent, one should consider the specific reactivity at interfaces. For example, the high temperatures processed in conventional sintering routes can induce the formation of undesirable interphases between components leading to a detrimental influence on the multimaterial assembly properties. We have then developed a manufacturing strategy based, on the one hand, on grain boundary engineering to design 0-3 type nanocomposites starting from core@shell nanoparticles and, on the other hand, on the implementation of hydrothermal sintering (Fig. 7.a) [43]. 
We have focused on the ( $\mathrm{La}, \mathrm{Sr}) \mathrm{MnO}_{3}$ (LSMO)-silica system because the introduction of the insulating silica phase at the grain boundaries of polycrystalline metallically conducting manganite promotes the spin-polarized tunneling between neighboring perovskite grains [44-51]. The macroscopic transport is consequently strongly dependent on external magnetic field, which makes such composites promising for spintronic devices. Hydrothermal sintering is suitable to fabricate 0-3 type composites with a relative density of approximately $80-85 \%$ where LSMO cores are uniformly and discretely embedded in the insulating matrix of three-dimensional-connectivity that originates from the silica shell densification [43]. Here silica also ensures the confinement of defects at the interfaces and prevents the core growth. Neither interphase formation nor evolution of core chemistry (manganese valency) was observed as the sintering mechanisms occur at the liquid/solid interfaces, i.e. the water/silica interfaces. Moreover, the thicker the silica shell, the more core@shell nanoparticles behave like silica nanoparticles with respect to hydrothermal sintering (Fig. 7.b,c). This tendency is attributed to the evolution of the compressibility of the core@shell nanoparticles as it strongly influences the intra grain stress gradient induced by external uniaxial compression, hence the dissolution/precipitation phenomena. In addition, one can also observe that depending on their compressibility, the materials will accommodate differently the released water transport, leading to an evolution of the porosity nature (mesoporosity or macroporosity).
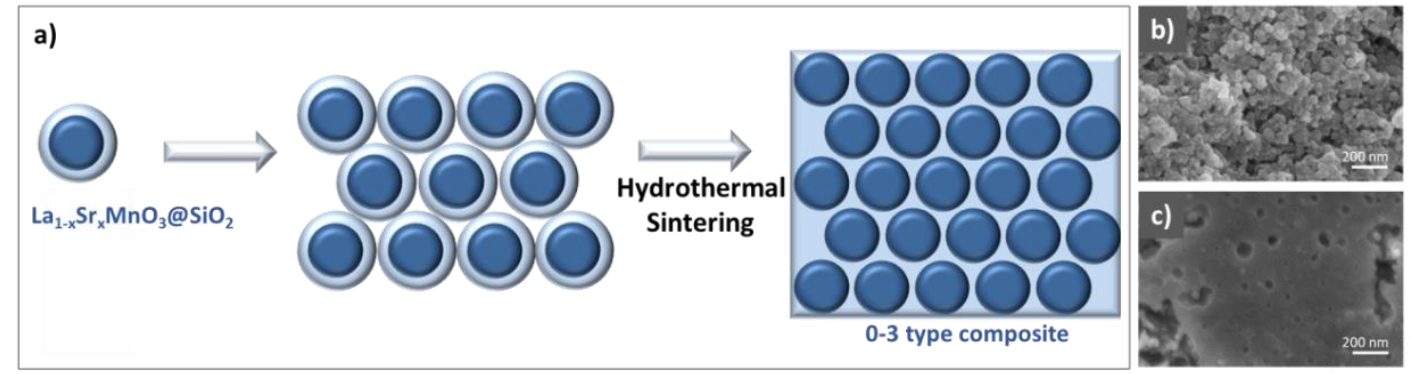

Fig. 7. a) Bottom up strategy for the elaboration of 0-3 type composites implementing hydrothermal sintering. Evolution of the microstructure of the composite after hydrothermal sintering $\left(300^{\circ} \mathrm{C}\right.$, $350 \mathrm{MPa}, 20 \mathrm{wt} \%$ of $0.2 \mathrm{M} \mathrm{NaOH}, 90 \mathrm{~min}$ ) according to the starting silica thickness: b) $5 \mathrm{~nm}$ and c) $10 \mathrm{~nm}$ [43]

Obviously, the bottom up strategy is intended to be extended to other systems. For instance, it should be specifically suitable for thermoelectric, multiferroic or piezoelectric complex multimaterials [52-53].

\section{3- Hydrothermal Sintering and Cold Sintering Processes : close cousins for complementary performances}

In June 2016, C. Randall et al. from Pennsylvania State University have reported impressive sintering results [54-63] (95\% of compactness reached on a large panel of ceramics and composites then evidencing device fabrication) with a process called the "Cold Sintering Process" (CSP) based on hydrothermal sintering. The explored temperature and pressure ranges are respectively $25-350^{\circ} \mathrm{C}$ and 
50-500 MPa, most of the experiments being set up below $200^{\circ} \mathrm{C}$ and $350 \mathrm{MPa}$. In 2017, Bouville and Studart, from ETH Zurich, claim the densification of vaterite at room temperature using CSP [64].

First of all, comparing energy merit in the different sintering techniques, the development of advanced sintering processes (Flash sintering, microwave sintering...) has led to a significant reduction in energy consumption compared to conventional sintering. CSP has been developed in this specific context and can be considered up to now as one of the most energy efficient technique [65]. Because hydrothermal sintering experiments are carried out in the same pressure and temperature ranges and with equivalent durations, this process also naturally appears as a promising solution to decrease the energy costs with, in particular, a single sintering step.

The mechanisms involved in CSP and hydrothermal sintering are the same but both processes differ from each other due to the balance between thermodynamics and kinetics that strongly influences the predominance of the involved elementary steps and may induce significant differences concerning solubility, dissolution and precipitation kinetics, pore shrinkage, water release and achievable densification.

- In the CSP process, the system is open and water becomes gaseous during the sintering. The temperature both accelerates the dissolution and quickly saturates the solution with the evaporation of the solvent driving the precipitation. The overall process is analogous to the densification of liquid phase sintering but with an enabling transient liquid phase that evaporates at low temperatures. The loss of water induces departure from thermodynamical equilibrium conditions, bringing a kinetic component to the CSP sintering process.

- In the case of hydrothermal sintering, the system is closed. As the applied pressure exceeds the saturation vapor pressure, the solvent remains liquid under subcritical conditions (or becomes a supercritical fluid above its critical point) and the densification is governed by thermodynamics. Here the main difficulty is related to the competition between the propagation of the densification and the solvent release: if the densification is too fast (enhanced by temperature), the microstructure cannot accommodate the induced fast water release and macroporosities are formed. Pressure then appears as the lever to control the water transport. On contrary, slower densification favors the elimination of water from the matrix and impedes the formation of macroporosities.

Consequently, an in-depth knowledge and the mastery of the balance between thermodynamics and kinetics will provide a powerful solution to optimize the densification, and control the grain size, the size distribution and the crystallinity of the precipitating phase.

\section{4- Future outlook and impact}

Hydrothermal sintering appears as an enabling technology as it will provide the means to increase the performance and capabilities of materials and sintering processes. In this way, the impact of this process can be expected multifaceted.

- Scientific and technological impact: our better understanding of the densification mechanisms during hydrothermal sintering will be a key in developing a clear roadmap to guide future studies of ultralow 
temperature sintering and offer widespread application prospects for a large variety of materials. In addition to a technological transfer to other materials such as complex oxides or non-oxide materials, we can foresee the development of a new technology to perform co-sintering of multiple materials to reach specific functionalities. One should notice that the process is obviously not restricted to nanomaterials. Moreover, given the compressibility of the material and the water release controlled by both pressure and temperature, new ceramic materials with controlled porosity can be designed. Finally, due to the enhancement of the reactivity at the interfaces in hydrothermal (or solvothermal) conditions, the possibility to bond different materials such as a metal with ceramic that has been densified in situ is of outstanding interest both from a scientific, technological and economical point of view. In this way industrial multistep processes could be replaced by a single hydrothermal sintering step.

- Economic impact: the economic impact of hydrothermal sintering is significant in the sense that it appears as a feasible route for cost-effective and sustainable energy ceramic manufacturing processing and integration that enables a broad range of applications, e.g. for the production of electroceramics. More precisely, short experiments at low temperature ensure lower energetic costs while the use of water as a solvent is associated with cheap consumables (packing seals). Obviously, hydrothermal sintering may have highly advantageous industrial fallouts, especially in the microelectronic and ceramic industries. In this way, this process unambiguously appears as an appropriate solution for the industrial production of small size pieces (up to a few $\mathrm{cm}^{3}$ ).

- Environmental impact: hydrothermal process does not generate any waste. Moreover, solvents define a major part of the environmental performance of processes in chemical industry and impact cost, safety and health. The use of water as a cheap, green and safe solvent makes hydrothermal sintering an environmentally friendly process.

As a consequence, hydrothermal sintering is a springboard for the design and fabrication of ceramics and complex multimaterials, integrating nanotechnology. It ensures a social and environmental responsibility as it is a low energy consuming process. Both the process and the related knowledge have been considerably improved these last years however better performances can be expected. For example, fast heating and cooling rates will be an asset to control the balance between thermodynamics and kinetics; the specific design of heating routes is therefore of great interest to master the grain morphology, the porosity and the nature of the precipitated phase. Moreover the development of in situ dilatometry measurements would lead to carry out the identification of the rate-controlling densification mechanisms. They will provide important experimental optimizations as they will allow visualizing more precisely the onset of shrinkage. The short-term challenge is then to transfer all the knowledge on hydrothermal and solvothermal processes acquired as part of the synthesis or crystal growth of size and/or morphology controlled materials. These specific conditions which contribute to an optimization of the reactivity at the solid/liquid interfaces are expected to make possible, on the one hand, to control the grain size from nanometric to micrometric and, on the other hand, to stabilize new phases during the precipitation step as evidenced in the case of $\alpha$-quartz. In 
conclusion, hydrothermal sintering should be considered as a chemically controlled process which opens up a particularly rich range of perspectives.

\section{Acknowledgments}

Authors gratefully thank Pr. Clive Randall and Dr. Jing Guo from Penn State University for fruitful discussions.

\section{References}

${ }^{1}$ A.V. Polotai, K. Breece, E. Dickey, C.Randall, A. Ragulya, J. Am. Ceram. Soc. 88 (2005) 3008

2 I.W. Chen, X.H. Wang, Nature 404 (2000) 168

${ }^{3}$ M. Cologna, B. Rashkova, R. Raj, J. Am. Ceram. Soc. 93 (2010) 3556

${ }^{4}$ Y. Takano, H. Takeya, H. Fujii, H. Kumakura, T. Hatano, K. Togano, H. Kito, H. Ihara, Appl. Phys. Lett. 78 (2001) 2914

${ }^{5}$ R. Chaim, A. Shlayer, C. Estournes, J. Eur. Ceram. Soc. 29 (2009) 91

${ }^{6}$ J.D. Katz, Annu. Rev. Mater. Sci. 22 (1992) 153

7 A. Mohanram, S.H. Lee, G.L. Messing, D.J. Green, J. Am. Ceram. Soc. 89 (2006) 1923

${ }^{8}$ D.J. Green, O. Guillon, J. Rödel, J. Am. Ceram. Soc. 28 (2008) 1451

${ }^{9}$ I.A. Ovid'ko, A.G. Sheinerman, Rev. Adv. Mater. Sci. 29 (2011) 105

${ }^{10} \mathrm{~K}$. Khalil, Ceramic materials-Progress in modern ceramics, InTech (2012) 65

${ }^{11}$ R. Chaim, M. Levin, A. Shlayer, C. Estournes, Advances in Applied Ceramics, 107 (2008) 159

${ }^{12}$ P. Palmero, Nanomaterials, 5 (2015) 656

${ }^{13}$ M.N. Rahman, Sintering of Ceramics, CRC Press: Boca Raton (2008)

${ }^{14}$ J.Gratier, D.K. Dysthe, F.Renard, Adv. Geophys., 54 (2013) 1

${ }^{15}$ E.H. Rutter, Tectonophysics., 14 (1972) 13

${ }^{16}$ X. Zhang, C.J. Spiers, C.J. Peach, J. Geophys. Res. 115 (2010) B09217

${ }^{17}$ J.P. Gratier, R. Guiguet, F. Renard, L. Jenatton, D. Bernard, J. Geophys. Res. 114 (2009) B03403

${ }^{18}$ J.P. Gratier, F. Renard, P. Labaume, J. Structural Geology. 21 (1999) 1189

${ }^{19}$ N. Yamasaki, K. Yanagisawa, M. Nishioka, S. Kanahara, J. Mater. Sci. Lett. 5 (1986) 355

${ }^{20}$ K. Yanagisawa,M. Sasaki, M. Nishioka, K. loku, N. Yamasaki, J. Mater. Sci. Lett. 13 (1994) 765

${ }^{21}$ K. Yanagisawa, K. loku, N. Yamasaki, J. Am. Ceram. Soc. 80 (1997) 1303

${ }^{22}$ N. Yamasaki, T. Weiping, K. Yanagisawa, J. Mater. Res. 8 (1993) 1972

${ }^{23}$ N. Yamasaki, T. Weiping, K. Jiajun, J. Mater. Sci. Lett. 11 (1992) 934

${ }^{24} \mathrm{~J}$. Li, T. Hashida, J. Mater. Sci. 42 (2007) 5013

${ }^{25}$ K.L. Montoya-Cisneros, J.C. Rendon-Angeles, Z. Matamoros-Veloza, A. Matamaros-Veloza, K; Yanagisawa, Ceram. Intern. 43 (2017) 11907

${ }^{26}$ N. Yamasaki, T. Kai, M. Nishioka, K. Yanagisawa, K. loku, J. Mater. Sci. Lett. 9 (1990) 1150

${ }^{27}$ A. Nakahira, S. Takezoe, M. Takimura, H. Nagata, Y. Yamasaki, AIP Conference Proceedings. 833 (2006) 56

${ }^{28}$ Y. Xie, S. Yin, H. Yamane, T. Hashimoto, T. Sato, Solid State Sci. 11 (2009) 1703

${ }^{29}$ K. Yanagisawa, M. Nishioka, K. loku, N. Yamasaki, J. Mater. Sci. Lett. 9 (1990) 7

${ }^{30}$ K. Yanagisawa, M. Nishioka, K. loku, N. Yamasaki, J. Mater. Sci. Lett. 12 (1993) 1073

${ }^{31}$ S. Katsuyama, Y. Takiguchi, M. Ito, Materials Trans. 48 (2007) 2073

${ }^{32}$ S. Katsuyama, Y. Takiguchi, M. Ito, J. Mater. Sci. 43 (2008) 3553

${ }^{33}$ S. Katsuyama, A. Kishida, M. Ito, J. Alloys and Compounds. 414 (2006) 215

${ }^{34}$ T. Onoki, K. Hosoi, T. Hashida, Scripta Mater. 52 (2005) 767

${ }^{35}$ XT. Onoki, S. Yamamoto, H. Onodera, A. Nakahira, Mater. Sci. Eng. 31 (2011) 499 
${ }^{36}$ G. Goglio, A. Largeteau, A. Ndayishimiye, M. Prakasam, French Patent Application FR17 /54585 (may 2017)

${ }^{37}$ I. Shimizu, Tectonophysics 245 (1995) 121

${ }^{38}$ A.Ndayishimiye, A. Largeteau, S. Mornet, M.Duttine, M.A. Dourges,..., C. Elissalde, G. Goglio, J. Eur. Ceram. Soc., 38 (2018) 1860

${ }^{39}$ S. Jana and S. Jana, Particulate Technology for Delivery of Therapeutics, Springer Singapore (2017)

${ }^{40}$ R.K. Iler, The chemistry of silica: solubility, polymerization, colloids and surface properties and biochemistry of silica, John Wiley and Sons (1979)

${ }^{41}$ A.Ndayishimiye, A. Largeteau, M. Prakasam, S. Pechev, M.A. Dourges, G. Goglio, Scripta

Materialia, 145 (2018) 118

${ }^{42}$ G. Demazeau and A. Largeteau, Z. Anorg. Allg. Chem. 641 (2015) 159

${ }^{43}$ A. Ndayishimiye, S. Buffière, M.A. Dourges, A. Largeteau, M. Prakasam, S. Mornet, O. Kaman, J.

Zdenek, J. Hejtmanek, G. Goglio, Scripta Materialia, 148 (2018) 15

${ }^{44}$ Z.C. Xia, S.L. Yuan, W. Feng, L.J. Zhang, G.H. Zhang, J. Tang, L. Liu, S. Liu, G. Peng, D.W. Niu, L. Chen, Q.H. Zheng, Z.H. Fang, C.Q. Tang, Solid State Commun. 128 (2003) 291

${ }^{45}$ W.J. Lu, Y.P. Sun, X.B. Zhu, W.H. Song, J.J. Du, Mater. Lett. 60 (2006) 3207

${ }^{46}$ A. Gaur, G.D. Varma, J. All. Comp. 453 (2008) 423

${ }^{47}$ C.S. Xiong, Y. Zeng, Y.H. Xiong, J. Zhang, Y.B. Pi, L. Zhang, J. Xiong, X.W.Cheng, F.F.Wei, L.J.Li, Physica B 403 (2008) 3266

${ }^{48}$ P.T. Phong, N.V. Khiem, N.V. Dai, D.H. Manh, L.V. Hong, N.X. Phuc, Mater. Lett. 63 (2009) 353

${ }^{49}$ D. K. Petrov, L. Krusin-Elbaum, J.Z. Sun, C. Field, P.R. Duncombe, Appl. Phys. Lett. 75 (1999) 995

${ }^{50}$ L. E. Hueso, J. Rivas, F. Rivadulla, M.A. Lopez-Quintela, J. Appl. Phys. 89 (2001) 1746

${ }^{51}$ D. T. Tran, T.H. Nguyen, H.M. Do, D.L. Vu, T.L. Phan, S.C. Yu, Adv. Nat. Sci. : Nanosci. Nanotechnol. 4 (2013) 035001

${ }^{52}$ S. Mornet, C. Elissalde, V. Hornebecq, O. Bidault, E. Duguet, A. Brisson and M. Maglione, Chem. Mater. 17 (2005) 4530

${ }^{53}$ C. Elissalde, U.-C Chung, G. Philippot, J. Lesseur, R. Berthelot, D. Sallagoity, M. Albino, R. Epherre, G. Chevallier, S. Buffière, A. Weibel, D. Bernard, J. Majimel, C. Aymonier, S. Mornet, C. Estournes, M. Maglione; J. Adv. Dielectr. 5 (2015)_Art. 1530001

${ }^{54}$ H. Guo, A. Baker, J. Guo, C.A. Randall, ACS Nano (2016) DOI: 10.1021/acsnano.6b03800

${ }^{55}$ J. Guo, H. Guo, A. Baker, M.T. Lanagan, E.R. Kupp, G.L. Messing, C.A. Randall, Angewandte Chemie Int. Ed. 55 (2016) 11457

${ }^{56}$ H. Guo, J. Guo, A. Baker, C.A. Randall, ACS Appl. Mater. Interfaces 8 (2016) 20909

${ }^{57}$ J. Guo, S.S. Berbano, H. Guo, A. Baker, M.T. Lanagan, C.A. Randall, Adv. Funct. Mater. 26 (2016)

7115

${ }^{58}$ H. Guo, A. Baker, J. Guo, C.A. Randall J. Am. Ceram. Soc. 99 (2016) 3489

59 J. Guo, A. Baker, H. Guo,M. lanagan, C.A. Randall, J. Am. Ceram. Soc. 100 (2017) 669

${ }^{60}$ S. Funahashi, J. Guo, H. Guo, K. Wang, A. Baker, K. Shiratsuyu and C. A. Randall, J. Am. Ceram. Soc., 100 (2017) 546

61 J. P. Maria, X. Y. Kang, R. D. Floyd, E. C. Dickey, H. Z. Guo, J. Guo, A. Baker, S. Funihashi, and C. A. Randall, J. Mater. Research, 32 (2017) 3205

62 D Wang, H Guo, CS Morandi, CA Randall and S. Trolier-McKinstry, APL Materials 6 (2018) 016101

${ }^{63}$ X. Zhao, J. Guo , K. Wang, T. Herisson De Beauvoir, B. Li, and C. A. Randall, Adv. Eng. Mat. (2018)

doi.org/10.1002/adem.201700902 (in print),

${ }^{64}$ F. Bouville, A.R. Studart, Nature Comm. 8 (2017) 14655

${ }^{65}$ D. S. B. Heidary, M. Lanagan, C. A. Randall, J. Eur. Ceram. Soc. 38 (2018) 1018 